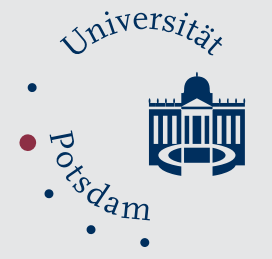

Philosophische Fakultät

Svenja Kranich

\title{
Functional layering and the English progressive
}

Suggested citation referring to the original publication:

Linguistics 51 (2013), 1, S. 1-32

DOI: http://dx.doi.org/10.1515/ling-2013-0001

Postprint archived at the Institutional Repository of the Potsdam University in:

Postprints der Universität Potsdam

Philosophische Reihe ; 110

ISSN 1866-8380

http://nbn-resolving.de/urn:nbn:de:kobv:517-opus4-93961 



\title{
Svenja Kranich
}

\section{Functional layering and the English progressive $^{1}$}

\begin{abstract}
In this article, it will be argued that the concept of functional layering - an extension of Hopper's (1991) concept of layering - can be fruitfully applied to understand the mechanisms behind the sometimes large and messy looking synchronic picture of diverse meanings which one and the same construction can fulfill at a particular point in time. The concept will be used to account for the meaning spectrum of the present-day English progressive, which, it will be argued, no monosemic approach to date can account for. Taking a look at the diachrony of the construction will help to reveal that the various "exceptions" found in the use of the progressive can be understood as reflections of different stages in its development. Older, less grammaticalized or less well-defined usage patterns thus often survive in certain restricted niches next to the newer, more grammaticalized or more clear-cut functions, representing different diachronic layers. In addition to this diachronic motivation for synchronic meaning variety, the article will also address the crucial question of how a present-day hearer of a progressive form is able to decode the specific meaning intended by the speaker based on contextual clues. The article ends with some suggestions for further applications of the concept of functional layering.
\end{abstract}

Keywords: grammaticalization, subjectification, semantic change, the English progressive construction, polysemy

Svenja Kranich: Institut für Anglistik und Amerikanistik, Universität Potsdam, Am Neuen Palais 10, D-14469 Potsdam, Germany. E-mail: svenjakranich@googlemail.com

1 I would like to thank the two anonymous reviewers for their insightful comments and criticism. Furthermore, I would like to express my gratitude to Jean-Christophe Verstraete and Viktor Becher, both of whom provided extremely helpful comments on earlier versions of this article, as well as to the participants of the international conference New Reflections on Grammaticalization IV in Leuven and the colloquium Corpora and the history of English. ARCHER 3 and beyond in Freiburg for their comments and questions. 


\section{Introduction}

Semantic descriptions of grammatical markers often seem to encounter the problem that they either neglect certain meanings for the sake of the elegance of the analysis, or else present a list of different uses the marker can be put to in context without being able to provide an explanation of why the co-existence of all of these functions is possible. In the present article, I will suggest that the reason lies in the traces of diachrony visible in the synchronic state-of-affairs: as Lass (1997: 9-16) has pointed out, apparent irregularities in present-day linguistic forms are often only explicable with reference to their diachronic development (cf. also Leiss 2004: 233). Numerous studies of grammaticalization processes have shown that grammatical(izing) constructions exhibit different functions at different stages of the grammaticalization process. Early on, pragmatic or more speaker-based meanings are typically associated with emerging constructions, while in later stages, more grammatical (i.e., paradigmatic, obligatory) functions crystallize (cf. e.g., Traugott 2010: 38-41; Diewald 2010). In this article, I will argue that it is not uncommon for older meanings of a construction to survive in certain contextual niches, even as the construction acquires a different predominant meaning. As a case study, I will look at the present-day meaning spectrum of the English progressive, which, it will be demonstrated, can be traced back to various semantic changes that accompanied the long-term process of grammaticalization. ${ }^{2}$

The present study will show how the concept of layering is useful for this type of semantic analysis, which attempts to provide a structured synchronic analysis of a construction's meaning against the backdrop of its diachronic development. Layering is one of the five principles of grammaticalization proposed by Hopper (1991) as an addition to Lehmann's (2002 [1982]) parameters. Hopper originally described layering as follows: "Within a broad functional domain, new layers are continually emerging. As this happens, the older layers are not necessarily discarded, but may remain to coexist with and interact with new layers" (Hopper 1991: 22). In the present article, the concept shall be used in a modified manner. Rather than applying it to new layers of form arising in the same functional domain, it will be used here to understand new layers of function that the same form comes to acquire over time. The same principle applies, however: as new meanings (more grammatical meanings through grammaticalization, more subjective

2 In the present approach, I do not attempt to draw a strict line between semantics and pragmatics. I consider a meaning of the progressive construction every function that the construction was shown to fulfill repeatedly in the corpus used for this analysis. Features of the co(n)text, as will become clear, are understood to activate a particular meaning. 
meanings through subjectification) emerge, older meanings are not necessarily discarded, but may remain to coexist and interact with the new functional layers. I shall refer to this principle as functional layering.

One might argue that of Hopper's five principles, it is actually the one of persistence, rather than layering that could be applied. However, persistence explicitly refers to the persistence of "some traces of [the] original lexical meaning" (emphasis mine) of a grammaticalizing or grammaticalized construction. This is not what will be discussed in the present article, which does not deal as much with the retention of lexical meaning as with the co-existence of earlier, less grammaticalized meanings and later, more grammaticalized meanings, as well as with different layers of subjective meanings. The metaphor of different "layers" building up over time seems particularly apt for conceptualizing this process and its synchronic result.

The present article will argue that the concept of functional layering is crucial for a proper understanding of the entire meaning spectrum of the present-day English (PDE) progressive, whose variety of uses has often posed a problem for approaches aiming at an analysis defining one basic core meaning. The claim I shall make here is that such approaches are inadequate, as they fall short in dealing with a construction whose various meanings reflect different diachronic stages.

The article is organized as follows: after this introduction, a survey of the most influential approaches to the present-day functions of the English progressive will be provided. It will become clear that none of these approaches is able to deal satisfactorily with all of the uses of the construction. Section 3 will present a model that accounts for the different meanings of the PDE progressive and offers a model of how the hearer of a progressive form is able to decode the intended meaning of the speaker. The analysis is supported by corpus data of written British English from 1950 to 1999 (the last half-century included in ARCHER-2, A Representative Corpus of Historical English Registers 2). ${ }^{3}$ Section 4 will then provide information about the different developmental time-lines of the diverse

3 ARCHER-2 consists of texts from diverse more formal (e.g., scientific and medical prose) and more informal registers (e.g., drama and private letters) and contains a British English and an American English part. The present study is based on the 1950-1999 section of the British English part (199,259 words), but also takes results from a large-scale analysis of all occurrences of the progressive in the British English part of ARCHER-2 into account, covering the period between 1600-1999 (altogether 1,363,056 words) (Kranich 2010b). Examples from ARCHER-2 cited in the present article are supplied with a reference in the form “archerii $1950-99 . b r e \backslash 1973$ trev.f9", which provides information about the half-century, the variety (bre $=$ British English), the exact year of publication or the date of the entry with regard 
meanings, the earliest of which date from Old English (OE) times, while the most recent one only properly establishes itself in the course of the 19th century. This section will substantiate the claim that functional layering represents a valid approach to the analysis of the present-day meaning spectrum. The state-of-affairs observable in English, with the progressive construction being used for both aspectual and subjective functions, is apparently not an isolated phenomenon, but can be observed in other (loosely related and completely unrelated) languages as well. Section 5 presents some thoughts on possible reasons for this phenomenon. Section 6 will conclude with a summary of the findings and some suggestions for the further applicability of the concept of functional layering.

\section{Previous approaches to the functions of the present-day progressive}

The analyses of the functions of the present-day progressive can be broadly classified into two types: first, those which wish to deduce all uses of the construction from one basic meaning (e.g., Bodelsen 1974 [1936-1937]; Dowty 1977; Palmer 1988; Granath and Wherrity 2008), and second, those which allow for a number of different meanings (e.g., Quirk et al. 1985; Leech 1987; Huddleston and Pullum 2002). Of the former, the majority refers either to the aspectual function of the construction (e.g., Dowty 1977; Smith 1997) or to specific properties of the situation. Approaches claiming that a specific property of the situation (or a specific property ascribed to the situation by the speaker) is decisive in the choice of a progressive most commonly make reference to (limited) duration (e.g., Joos 1964; Mufwene 1984; Palmer 1988) or to dynamism (e.g., Žegarac 1993; Goosens 1994; Chilton 2007). Others see the difference between progressive and non-progressive forms as a contrast between more objective statements of fact, for which nonprogressive forms are used, and more subjective descriptions, which are expressed with the help of the progressive (e.g., Bodelsen 1974 [1936-1937]; Storms

\footnotetext{
to diaries, the abbreviated name of the author, and the abbreviation for the particular text in the corpus. The letter at the end of each reference provides information about the genre:

d - drama

$f-$ fiction

$\mathrm{h}$ - religious sermons

j - journals and diaries

$\mathrm{m}$ - medical texts

$\mathrm{n}$ - newspaper writing

$s-$ scientific texts

$\mathrm{x}$ - private letters
} 
1964; Durst-Andersen 2000, the latter stressing the statement-vs.-description contrast more strongly than an objective-vs.-subjective distinction).

None of the monosemous approaches can account for all observable uses of the English progressive. Let us start with the approaches relying solely on aspectual distinctions. These approaches are based on the idea that the progressive construction expresses either general imperfective or progressive aspect. Both aspectual meanings have in common that the proposition refers to a situation without its endpoints. In contrast to general imperfective aspect markers, progressive aspect markers are typically used only with dynamic situations (cf. Comrie 1976). ${ }^{4}$ Both approaches can deal with the contrast between progressive and simple form in Example (1):

(1) a. Julia made some tea when I came home.

b. Julia was making some tea when I came home.

The progressive in (1b) marks the situation [Julia make tea] as being in progress, as the second situation, the speaker's coming home, occurs. In (1a), on the other hand, the event [Julia make tea] is viewed in its totality, and thus the second situation is interpreted as having occurred before it (and may be pragmatically inferred to be its cause). The difference between the two meanings is most adequately described by labeling it an aspectual distinction, as opposed to making reference to duration (in both cases, (1a) and (1b), the situation [Julia make tea] is conceptualized as having limited duration).

Approaches which acknowledge only the aspectual meaning of the progressive run into problems, however, when confronted with uses of the type presented in (2)-(4):

(2) a. Michael always takes cigarette breaks.

b. Michael is always taking cigarette breaks.

(3) a. I hope you'll be around.

b. I'm hoping you'll be around.

(4) a. ?When he says "You're a great mate", he really says "I don't fancy you".

b. When he says "You're a great mate", he's really saying "I don't fancy you".

4 For a more detailed discussion of the progressive-imperfective distinction, cf. Kranich (2010b: 30-35), where an extensive overview of different approaches to the semantics of the PDE progressive is provided (Kranich 2010b: 23-76). 
None of these examples can be explained satisfactorily through an analysis that relies on aspect, i.e., an analysis that predicts that the form is only used for dynamic situations (and some temporary states) which are ongoing at topic time (TT). ${ }^{5}$ In fact, Examples (2a) and (2b) both refer to habits. Both examples in (3) refer to a stative situation. In the minimal pairs presented in (2) and (3), all situations verbalized hold throughout topic time, regardless of whether the simple form or a progressive is used. This therefore cannot be the decisive criterion distinguishing progressive use from use of the simple form. Looking at (4), one may note that the use of the simple form actually sounds a little odd. Once again, the function of the progressive here does not seem to be to express the ongoing, dynamic nature of the second mentioned event. Rather, it seems to mark that the speaker is offering her more subjective interpretation of the first, real event by presenting it as equal to the second, non-real event.

If we now turn to approaches that rely exclusively on a specific characteristic of the situation, we are forced again to recognize that these are not able to deal with all uses of the progressive construction. The most prominent approaches in this category rely either on dynamism or on duration (either the general property "durative" or the idea of limited duration). Concerning dynamism, one may say that the situation in (3) [Speaker hope $\mathrm{x}$ ] does not appear to be any more dynamic in (3b) than that in (3a). Dynamic situations are those which require energy input in order to continue, e.g., building a house, running. Although regarding private states such as hoping, it is diffcult to say whether they fit this definition of dynamic predicates in some subtle way, it seems clear to me that the sentences in the progressive and the non-progressive do not differ in this respect. What the progressive appears to add to the overall meaning is a certain note of tentativeness to the expression of hope (cf. Quirk et al. 1985: 210, Mair and Hundt 1995: 119). But this type of hedging function does not seem to alter in any way the dynamism of the situation depicted. I cannot see any clear connection be-

5 The terminology used here is based on Klein (1994). Topic time (TT) is defined as "the time for which the particular utterance makes an assertion" (Klein 1994: 37). In this view, tense relates TT to time of utterance (TU), while aspect describes the relationship between TT and time of situation (TSit) (Klein 1994: 6). We may illustrate this model by returning to our example sentences. In both (1a) Julia made some tea and (1b) Julia was making some tea, the past tense situates the TT before the TU, i.e., an assertion is made by the speaker for a time preceding the moment of talking about the situation. The simple past in (1a) views the situation perfectively: TSit is fully included in TT, i.e., an assertion is made about a whole, bounded situation. The progressive, on the other hand, views it imperfectively: TT is included within TSit, i.e., an assertion is made about only part of the situation, excluding the endpoints. 
tween hedging (making a statement more vague) and dynamism (referring to a situation that requires an input of energy to continue) (pace Rydén 1997: 423424).

As far as the criterion of duration is concerned, it would appear that most uses of the progressive do indeed make reference to situations that are [+ durative]. However, this is not equivalent to saying that the meaning of the progressive is duration. If one looks at the minimal pairs in (2) through (4), one must note that all of the situations referred to are [+ durative]. This is therefore not what distinguishes instances where the progressive is used from those which make use of the simple form. Limited duration also fails to help with these examples. For instance, with regard to the pair in (3), it is doubtful that the real difference lies in limited versus unlimited duration: the situations of hoping referred to in (3a) and (3b) could very well be of equal length. Similarly, the difference between (2a) and (2b) cannot be adequately tackled using the idea of duration either: in both cases, habits are referred to which are claimed to be general (i.e., not of particularly limited duration). Williams (2001) proposes "susceptibility to change" as the basic meaning of the progressive, combining features from aspectual analyses and analyses based on the concept of limited duration. However, his analysis of examples similar to those presented in (2a) is not convincing. Williams (2001: 104-105) argues that the simple form depicts the habit as more permanent, while the progressive presents the habit as probably "relatively recent" and "a possible end to the habit is envisaged through the use of the progressive". Having studied many instances of this type (Kranich 2007), I can find no evidence of either of these semanto-pragmatic effects. While Williams' (2001, cf. also 2002) analyses of the different uses of the progressive are often very insightful, it seems as if, in this case, he has fallen into the trap described by Hatcher (1974 [1951]: 189) as an underlying danger of many monosemic accounts of the progressive, i.e., "the tendency to become infatuated with theories and labels". That is, one ends up trying to make sense of the use of a construction in a particular context in light of one's own personal academic convictions or emphases, even when, looking at the data more neutrally, one would have to acknowledge that the choice of the construction in the context in question is determined by a different factor. In the case of progressive + always constructions, the difference between instances such as (2a) and (2b) appears to lie in the expression of speaker attitude, which we will come back to later in this section.

Apart from such subjective uses as seen in (2b), another strong argument against transience or limited duration as the basic meaning of the progressive comes from the possibility of utterances such as (5):

\section{(5) The universe is forever expanding.}


This example is taken from Ljung (1980: 28), who explains its occurrence as follows:

[I]t is part of our knowledge of the world that events progress [...] [and that] this progression from beginning to end does not take very long. Because of this, it is natural to associate all dynamic constructions with temporariness. However, it is also part of our knowledge that the progression from beginning to end may sometimes take very long, and it is not inconceivable that there are events which go on forever. (Ljung 1980: 28)

Therefore, we can conclude that situations referred to using the English progressive are generally conceptualized as dynamic and hence typically as of limited duration; this, however, represents a restriction of the applicability of the construction and not the meaning of the construction. This is a constraint typical of progressive aspect markers as opposed to general imperfective markers (cf. e.g., Dahl 1987 [1985]: 93; Comrie 1995: 1245).

If we now turn to approaches that only refer to the more subjective nature of the progressive, we can see that they are helpful for understanding the uses in (2) through (4). In (2b), Michael is always taking cigarette breaks, the progressive provides an expression of the speaker's attitude towards the state of affairs which is absent from the example with the simple form in (2a): in (2b), we understand that the speaker negatively judges the habitual activity referred to (cf. Leech 1987: 34; Kranich 2007). The difference between (3a) and (3b) cannot be attributed to the presence or absence of negative speaker-attitude. Rather, as pointed out above, the use of the progressive renders the expression of hope more tentative and thus, in some contexts, more polite. The use in (4b), finally, can be analyzed as an expression of subjective interpretation. The speaker first offers an objective description of a situation and then presents her own subjective interpretation of what the situation amounts to. Ljung describes this use as follows: “The A part expresses the observed behavior, the B part sums up or interprets this behavior and the predicate used for this summing up or interpreting is invariably put in the progressive” (Ljung 1980: 70-71; cf. also König 1980).

Ljung also points out that this function may be the one typically observable in the (diachronically relatively late) use of the progressive of full verb be. Ljung (1980: 43) observes that the progressive of be generally occurs with "covert predicates", i.e., predicates referring to situations which are not immediately perceivable by means of the five senses but require a certain subjective interpretation. If one looks at the acceptability of different types of predicative adjectives with the progressive of be, one will note that adjectives referring to properties which are not obvious but rather reflect a speaker's judgment occur easily in the construction, while adjectives that refer to "objective" properties, verifiable by the five 
senses, seem odd at best (cf. Quirk et al. 1985: 202). Some examples are presented below:

(6) Ellen is being nosy.

(7) Kalynda is being clever.

(8) *? Ellen is being pregnant.

(9) *?Kalynda is being brunette.

The strangeness of Examples (8) and (9) point to the inadequacy of the view that the restriction of the progressive of be to certain predicates can be explained with reference to limited duration, since (8) is clearly a temporary condition (and (9) could also be temporary, if the speaker knows that Kalynda has dyed her hair and will change her hair color again soon; the progressive would nevertheless not be used). In fact, (8) would represent an acceptable utterance in certain contexts, e.g., Ellen is crying again? Oh well, she's just being pregnant. But this would also correspond with the prediction, because in this special use, [Ellen be pregnant] represents a subjective interpretation of an observable situation [Ellen cry again]. Note also that in such special uses, the predicative adjective would exhibit other features not associated with the normal use of pregnant, e.g., gradability (Ellen is crying about nothing again. She's being so pregnant!).

While thus also helpful for the interpretation of the progressives of be, the analyses based on the objective-subjective dichotomy still cannot be used to explain every use of the progressive. They do well with the minimal pairs in (2) through (4), but fail to account for uses of the type presented in (1). Here, the difference between Julia made some tea and Julia was making some tea cannot be found in differing degrees of speaker-involvement or emphasis. Instead, the difference lies solely in the temporal sequentiality of the two situations being referred to. The assertions in (1a) and (1b) simply make reference to different states of affairs in the reference world. Thus, they also constitute evidence against the assumption of a general connection between progressive aspect and emphasis or pragmatic salience. ${ }^{6}$

The discussion so far should have made clear that an approach to the semantics of the PDE progressive that allows for polysemy is advantageous. Polysemic

\footnotetext{
6 In Güldemann's (2003) view, some subtle emphatic component can be detected even in the aspectual uses of a progressive marker, especially, however, in present tense contexts. Yet also in present tense contexts, the meaning of the English progressive often appears to be purely aspectual, as in the following example from the corpus The water tank is above the room they are talking in. (archerii 1950-99.bre\1964berg.f9). Here, the progressive marks the ongoing nature of the event, while a simple form in this context would refer to a habitual state of affairs.
} 
approaches can be found in reference grammars such as Quirk et al. (1985: 197215) and Huddleston and Pullum (2002: 162-172), who offer an overview of the diverse uses of the progressive. Quirk et al. (1985: 210) begin by stating that the progressive can express duration, limited duration and incompletion (cf. also Leech 1987), but also discuss some specific meanings under the heading "other uses", which cannot be related to these, such as the subjective use of the type exemplified in (3b). Huddleston and Pullum (2002) differ from Quirk et al. in that they do refer to one basic meaning, the expression of progressive aspect (and some implicatures derived from this meaning, such as limited duration), but also go on to list further, non-aspectual uses of the progressive, and they note "an emotive overtone" in uses such as that seen in (2b) (Huddleston and Pullum 2002: 166). Both reference grammars provide adequate practical guidelines for the usage of the progressive. As far as linguistic analysis is concerned, however, these descriptions are still lacking in that they fail to offer unified accounts of how all the meanings interact and how hearers of a progressive are able to make out the meaning intended by the speaker.

Outside of reference grammars, Rydén's (1997) analysis comes closest to the approach advocated here. In an article with the self-explanatory title "On the panchronic core meaning of the English progressive", Rydén suggests that the progressive has and always has had a double meaning, one "aspectual", the other "attitudinal", both of which he relates to the core function of "dynamicness". He explains:

[I]ts potential performance spectrum is very wide, within a core meaning or core function of DYNAMICNESS or DYNAMIC PROCESS as working essentially in two "facets", one actionfocussed (with the progressive used as a marker of temporality), the other attitude-focussed (with the progressive used as an attitude marker, for subjective expression on the part of the speaker). (Rydén 1997: 426)

There are, in my view, two problems with this analysis. Firstly, the concept of dynamism on which it is based is very broad. It is not clear to me to what extent dynamism, defined here as the nature of a situation requiring an input of energy, is connected to subjectivity, i.e., the linguistic expression of the speaker's personal interpretation and attitude towards situations. The second problem resides in the "panchronic" nature of Rydén's assumed core meaning, since dynamism is only a typical characteristic of situations referred to by the progressive in modern English. In $\mathrm{OE}$ and Middle English (ME), on the other hand, the progressive is not yet associated with dynamic processes, as one can see in its use to refer to states of unlimited duration, e.g., for geographical descriptions (cf. Traugott 1972: 90; Mossé 1938: 181-187). The idea of a "panchronic core meaning” seems inappropri- 
ate for a form which has undergone a long-term grammaticalization process and with it several functional changes. The view that both aspectual and subjective meanings have played a role ever since the emergence of the construction is shared here; but in the present approach the diachronic changes both concerning the exact nature and the distribution of the two types of meaning are considered crucial (for more detail, cf. Kranich 2010b).

A further point not addressed by Rydén is the question of how hearers of a progressive can determine which meaning to assign to the construction. I take the standpoint that only one meaning should be assigned to one occurrence of the progressive form, while other authors assume that a progressive can be both aspectual and attitudinal, to use Rydén's terminology (e.g., Güldemann 2003; Smitterberg 2005). But if a progressive form, as in PDE, is grammaticalized to such an extent that its prototypical function is to mark aspect, I cannot see how a hearer is supposed to know when it is meant to function additionally as an emphatic device. ${ }^{7}$ I therefore assume subjective meanings in PDE only where aspectual readings are not appropriate (as will be made clearer in Section 3).

To sum up, what is lacking to date is an analysis of the progressive that can account for all of its functions while at the same time presenting the rationale behind the different uses of the form and their relations to one another. A successful model also needs to address the question of how the hearer of an utterance containing a progressive can decode the meaning intended by the speaker. In the following sections, I will try to provide an analysis which satisfies these requirements.

\section{The meanings of the progressive in PDE}

I will start this section by proposing a model for the organization of the meanings of the present-day progressive, illustrating how a hearer may be able to decode the meaning of the progressive intended by the speaker. Subsequently, I will

7 Particularly in those contexts where using the progressive is obligatory in PDE, it is clear that you cannot invest the progressive form with additional emphatic meaning, no matter how emotionally loaded the context is. If you have, for instance, an utterance like Oh my gosh, have you seen that freak over there? He's licking his poodle's paws!, then no matter how many clues the context (very odd incident) and the co-text (exclamation, emotionally-loaded lexis) offers, you cannot say that any of the emphasis in the statement comes from using the progressive. The progressive is simply obligatory in 20th and 21st century English if one wishes to refer to a single ongoing event. It wouldn't be grammatically acceptable to say *Look at him! He licks the poodle's paws!, and the progressive would be used just as well for a neutral statement about an unremarkable event, like He's waiting outside the shop. 
present some quantitative results on the distribution of these meanings across progressive instances from late 20th century data, which will serve to corroborate the plausibility of the model.

Although I assume the model bears some resemblance to real cognitive processes, it is certainly not to be understood as a one hundred percent accurate rendition of the actual processes in a hearer's mind. In particular, I would only claim that the first step a hearer takes is to check whether the progressive fulfills its default function of marking progressive aspect. As for the further steps, it is conceivable that they take place simultaneously, or that they take place in an order different from that presented here (e.g., the formal salience of the combination will/shall + progressive infinitive does indeed, as remarked by one reviewer, make it likely that this type of progressive is captured almost immediately). I still believe that the model is justified in providing an overview of how, theoretically, the different functions of the progressive can be deciphered (not necessarily of how they are deciphered) - an overview which is lacking in other polysemic treatments of the progressive.

Six different (though related) meanings are distinguished in the present approach, which can be grouped into two larger categories: aspectual meanings and subjective meanings (both groups with three subtypes). The aspectual meaning represents the main meaning of the progressive in PDE and is in fact its name giver: the default function of the construction is the expression of progressive aspect, i.e., conveying the meaning that a dynamic situation is in progress at TT. Example (1b) represents a typical instance. The first step in decoding the progressive is thus: if it is possible, from the context and the lexical input, to ascribe progressive aspectual meaning to the construction, do so.

This model allows one to classify instances which are less prototypical, but where the assignment of progressive meaning is still possible, as instances of the default case, i.e., as instances of progressive aspect. Such less clear-cut cases include, for instance, the use of the construction for temporary habits, as the following example illustrates:

(10) The washing-machine had long since ceased to operate, but he was still paying monthly instalments to the United Dominions Trust hire-purchase organisation.

(archerii \1950-99.bre\1973trev.f9)

The expression of temporary habits can be seen as an extended application of the progressive meaning, as this type of use is not clearly different in kind from other uses of progressive aspect. It can, for instance, be compared to the reference to accomplishment situations where it is evident from world knowledge that reach- 
ing the result will take a long time and that the subject is not continuously engaged in the activity that is meant to lead to the result. An example can be seen in the following instance:

(11) In the biggest operation of the war 25,000 American and South Vietnamese troops are reducing the "Iron Triangle", the Viet Cong's jungle stronghold 4 miles up-river from Saigon.

(archerii \1950-99.bre\1967stm1.n9)

In both types of use, temporary habitual situations as presented in (10) and accomplishment situation types of long duration as presented in (11), the situation can be viewed as dynamically in progress, although actual bouts of activity are interspersed by periods where the activity is not ongoing.

Cases for which elements of the aspectual meaning, though not the whole definition (dynamic + ongoing), can adequately be applied fall into two groups: first, instances in which the situation referred to holds or is maintained at TT, but is not properly dynamic ("general imperfective" uses) and second, those where even though the aspectual meaning of "ongoingness" at TT cannot be fully applied, some meaning derived from it can be (“derived aspectual” uses).

If the hearer thus decides that the progressive aspect meaning is not fully applicable, she may ask herself whether it is possible to ascribe part of the default meaning to the use. Is it possible to say that the state-of-affairs referred to holds at TT without it being typically dynamic? In this case, the use is a general imperfective, as in the following example:

(12) I can see them from where I'm sitting. [. . .] He is wearing outdoor clothes and carries a large brown paper bag. (archerii \1950-99.bre\1961simp.d9)

Stative situations to which the progressive is applied generally have at least the temporary nature in common with prototypical dynamic situations, as is the case in both progressives present in (12). Verbs typical in this context often come from the category referred to as "stance" by Quirk et al. (1985), which they view as "intermediate between the stative and dynamic categories" (Quirk et al. 1985: 205). The category includes verbs of position such as sit, stand, lie, as well as live when used for a temporary habitation.

These predicates do not represent prototypical states, insofar as an endpoint of the situation seems to be inherently envisaged, at least when they are used with animate subjects, which is when they normally occur in the English 
progressive (as far as the no-longer-animate Frank in Example 14 below is concerned, his being removed from the floor in the near future is also likely).

Michaelis (2004: 37) has suggested that these verbs, when occurring in the progressive, should in fact be classified as activities (i.e., the situation type defined as atelic and dynamic which applies to such predicates as run in the park, work, play ball). ${ }^{8}$ This would mean that uses as observed in (12) could simply be subsumed under the "progressive" rather than the "general imperfective" category. However, stance verbs and similar stative predicates of limited duration (such as wear) do not fulfill the criterion of being dynamic, as the situations referred to do not require energy input in order to continue. Another argument against viewing this type of predicate as an activity comes from the fact that more prototypical progressive markers than the English one (which is an "extended progressive", see Heine 1994: 280) do not accept such predicates in the progressive, as the following examples illustrate:

(13) `?Je suis en train de porter une jupe noire.

'I'm wearing a black skirt.'

(14) *?Frank ist am tot auf dem Boden liegen.

'Frank is lying dead on the floor.'

8 For Michaelis (2004), progressive-form state predications do not represent temporary states, but refer to homogeneous activities. They "are enabled to continue by the energy input of an animate entity" (Michaelis 2004: 37). However, situations in which drinks sit on tables and men lie dead on the floor (both expressible with the help of a progressive) do not seem to fulfill this criterion. In order to refute such counterarguments, Michaelis (2004: 37) justifies her classification of similar examples as homogeneous activities by stating that "[t]he subject denotata of such predications are participants in a causal chain, whether they are agents, effectors, or objects which an agent has oriented or configured in a specific way (e.g., socks which are in a bundle are located on the floor but not lying on the floor)". This qualification, however, seems to render the concept of dynamism and agentivity very broad and rather vague, as a great proportion of inanimate objects in stative situations can be said to have been "oriented or configured in a specific way" by some agent at some point. Thus, it is also possible to say that this definition applies to the example presented by Michaelis as unacceptable: ${ }^{*} \mathrm{His}$ hair is being green this semester: an agent had been involved in configuring the subject of the predication (i.e., the hair has been dyed by an agent). Michaelis' epistemologically-based classification is certainly not without justification from a general cognitive point of view. However, in view of the observed behavior of different types of aspectual markers (imperfective vs. extended progressive vs. progressive) with respect to the situation types, I find that a classification based on a more narrow definition of dynamism works better (see also the German and French examples (13) and (14) and the typological evidence adduced by Dahl 1987 [1985]). 
The use of verbs like wear and stance verbs like lie is just as unacceptable (or at best marginally acceptable) for the French être en train de construction as for the German am-progressive. To my mind, this justifies the classification of the English uses as "general imperfective" instead of "progressive".

Should the hearer of a progressive decide that an interpretation of the meaning as "not a typical dynamic event, but does hold at TT" is not appropriate either, she needs to check whether other features of the aspectual meaning can help to account for the use of the progressive. If the answer is "yes", the progressive is a "derived aspectual" one. Three subtypes of derived aspectual meanings can be distinguished, differing from one another in form: first, instances in which the progressive stands on its own (often modified by a future time adverbial) and has the meaning of "near future", second, instances in which the progressive is modified by will or shall with future meaning, and third, instances in which the progressive is combined with a perfect.

"Near future" can be assumed to be closely related to the progressive aspectual function, since the "near future" use of the progressive often denotes a situation which is firmly planned or may already be conceptualized as in progress, e.g., because preparatory activities are already ongoing. ${ }^{9}$ Leech et al. (2009: 133) speak of "a metonymic extension of the basic meaning of the progressive". This can be seen in Example (15) below:

(15) The day ended with the sad news that Dick is leaving to go to a rehabilitation center in N.H., for children.

(archerii \1950-99.bre\1976horn.j9)

Combinations of the progressive with future-time uses of will and shall "indicate[... .] that a predicted event will happen independently of the will or intention of anyone concerned" (Leech 1987: 68). This can be seen as related to its function of presenting a situation as already in progress: if one says that the situation will be in progress in the future, this turns the statement more into one referring to a situation that will as a matter of fact arise, than if one says that the situation will occur, which makes the proposition more of a prediction. The modal meaning of will and shall can also still occasionally be visible in combinations with the simple infinitive (e.g., Will you do this for me?) but not with the progressive

9 The term near future is put into quotation marks in order to draw attention to its vague nature. There are no clear objective criteria as to how near in the future the envisaged event must be situated to make use of the progressive appropriate. The decisive factor appears to be the subjective conceptualization of the event as near by the speaker. 
infinitive (cf. also Leech et al. 2009: 141). The following use represents a clear example:

(16) I got back here to more bills, and to hear that the bailiffs will be moving in unless I pay what I can never pay because I have no money at all [. . .]. (archerii \1950-99.bre\1952thom.x9)

Considering the meaning of the combination perfect + progressive, one can observe a connection to the predominant aspectual meaning of the progressive, but it remains rather unspecific. The combination can have a number of possible effects, such as the expression of absence of result, focus on the activity as such (rather than on the result), focus on concomitant effects, or focus on duration (cf. König 1995: 162-163). These meanings should be understood as being pragmatically rather than semantically determined. The different meanings can be derived from the combination of the meanings of the progressive and perfect, but only the context can offer clues as to the actuation of one of the possible meanings. Possible meanings of perfect + progressive range from ones very closely associated with the progressive aspectual function to rather vague semantic effects such as focus on duration. The following two examples are cases in point:

(17) I have been eating too much. When you pay about two hundred and forty pounds for a ticket, you try to get your money's worth out of sheer meanness. (archerii \1950-99.bre\1963whit.j9)

(18) The NAO, the investigative arm of the Comptroller and Auditor General, who is Parliament's public spending watchdog, has been examining the use of staff by Whitehall. It concluded that the Home Offe, which runs the Passport Offc e, had a questionable record in planning its use of manpower. It noted that in contrast to other parts of the government machine "productivity in the Passport Department has not increased in recent years”. (archerii \1950-99.bre \1989tim1.n9)

The impact of the progressive in (17) is fairly closely related to the meaning "progressive aspect": it signals that the situation is iterative, ${ }^{10}$ implies certain con-

10 The progressive ascribes iterative character to a situation only under certain conditions, namely either when the predicate is punctual (e.g., Jane was knocking vs. Jane knocked on the door) or when a perfect form could otherwise be interpreted as "existential perfect", i.e., as merely indicating that the situation has occurred at some indefinite time prior to the time of the utterance (e.g., I have eaten lobster before vs. I have been eating lobster all week). 
comitant effects, ${ }^{11}$ and allows the situation to be understood as potentially unbounded (i.e., having not yet come to an end within TT). With respect to the use in (18), on the other hand, all one can say is that the progressive places a certain emphasis on the duration of the examination, and potentially also on the duration of the event examined (the failure to increase productivity within the last years). None of the other effects of the combination perfect + progressive (absence of result, concomitant effects, unbounded situation) can be detected.

Cases in which an application of the aspectual reading in toto or in parte is impossible require a different interpretation. In such instances, the subjective meanings of the progressive will be activated. The hearer must now check whether the progressive is used with an ALWAYS-type adverbial, i.e., an adverbial meaning 'always' or having a very similar meaning (e.g., continually, forever, all the time, etc.). In these cases, the adverbial is used hyperbolically. In combinations with such an adverbial, the progressive often does not have its aspectual meaning. (In cases where it does have the aspectual meaning, as in Example (5), this meaning would have already been decoded in a previous step in the interpretation process according to the present model.) ${ }^{12}$ Instead, in PDE, the combination typically expresses a negative speaker-attitude, as is the case in (2b) above and in the example below:

(19) [...] and in order to make one's way to mosques and market-places one leaps from rut to rut and from stone to stone [. . .] and one's neck is being continually nuzzled by donkeys, mules, and camels.

(archerii\1950-99.bre\1950macl.j9)

11 The designation of concomitant effects can be linked to the meaning of "progressive aspect" insofar as such effects can be understood as "partly conditioned outcomes", i.e., as effects "having arisen somewhere within the event's coming-to-be-phase, i.e., an outcome conditioned by only part of the event" (Bégin 1996: 46, 49). Bégin (1996) views this as the general meaning of the combination perfect + progressive. However, if one looks at an instance such as (18), one cannot detect any reference to any kind of result of a partial event or concomitant effect.

12 The observation that progressive + ALWAYS combinations can also have aspectual meaning makes it preferable to assume that the hearer will still have to follow all the steps described for the decoding processes. If we assumed that the hearer can immediately identify the combination as a construction of its own with its own special meaning as suggested by one reviewer, the hearer would fail to analyze uses of the type The universe is forever expanding correctly. 
When no always-type adverbial is present, the hearer must check whether the progressive occurs with a more neutral description of a situation which it can be seen to interpret or whether it can serve to interpret something retrievable from the ongoing communicative situation. An example of the former type, in which the progressive interprets a situation verbalized in the previous discourse using a simple form, was presented in (4b) above. (20) below offers an example of an interpretative progressive in which the speaker interprets a preceding speech act. The utterance containing the progressive serves to mark the speaker's subjective interpretation of the entire previous turn of his interlocutor.

(20) ...Yes, I'm a plop, Hench. Whom one can now define, after so many years ploppity lived, as a chap who goes straight from masturbation to matrimony to monogamy.

SIMON. Oh, now there I think you're underestimating yourself. (archerii\1950-99.bre\1975gray.d9)

If none of the meanings described so far can be ascribed plausibly to the progressive, the hearer can deduce that the speaker merely uses the construction to give some more subjective flavor to the expression of the situation. This can either produce a more tentative reading or an emphatic meaning, depending on the lexical verb used. Hope typically seems to trigger a tentative interpretation, but this type of progressive can also occur in contexts in which the situation expressed by the predicate seems to be emphasized, as in (21) below. This rather vague subjective meaning can only be activated when neither the more typical aspectual meanings nor the more clear-cut subjective meanings can be ascribed to the construction in the given context. It is therefore to be expected that the contexts for this rather vague (and, as we will see, old) meaning of the construction are few in PDE, where the aspectual use of the construction is obligatory in certain contexts and the interpretative meaning the clearly dominant one of the subjective meanings (cf. Table 1 below). Indeed, the subjective meaning of this type seems to be restricted mostly to stative situations of undetermined duration, where aspectual progressives are uncommon, such as with the verbs hope or long, as exemplified in (21):

(21) My dear Henry - I was hoping that by now you were a settled family man and were going to sit down and give us the great fireside books of your later period. You can't start all over again [. . .] (archerii\1950-99.bre\1951durl.x9) 
Summing up the discussion so far, to arrive at the appropriate interpretation of a progressive construction, the hearer goes through a decision process that scans world knowledge and contextual information for relevant clues. This decision process can be modeled as visualized in Figure 1.

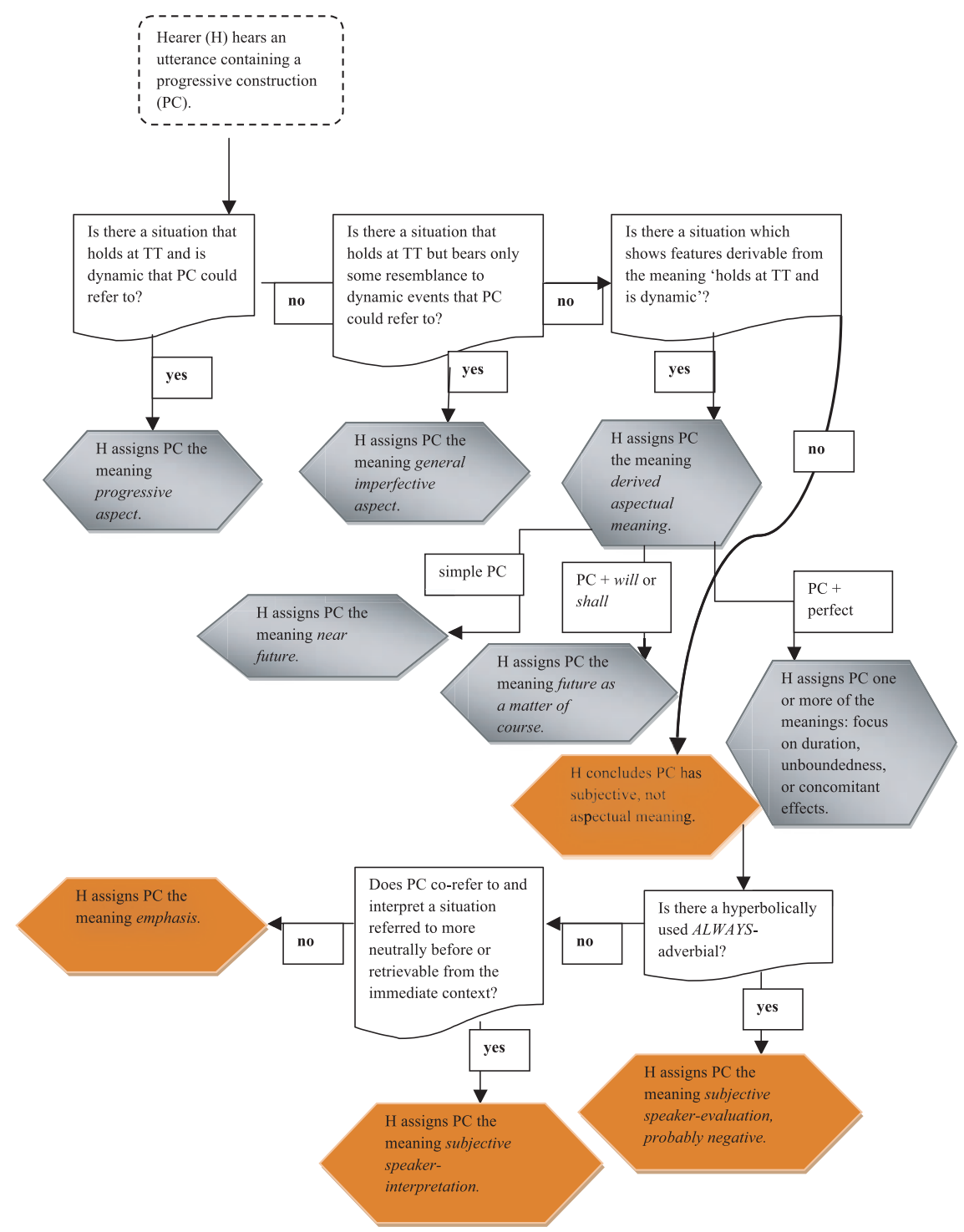

Fig. 1: A model of the decoding process needed to establish the meaning of the progressive 
Let us now turn to the results of the quantitative analysis of all instances of the progressive in British English in the time-span 1950-1999 from ARCHER-2 $(\mathrm{n}=783$ ). One can see that all meanings discussed so far were found in the period 1950-1999 in ARCHER-2, but that considerable differences exist in their relative proportions.

\begin{tabular}{|l|c|}
\hline & $\begin{array}{c}\text { Progressives in } \\
\text { ARCHER-2 1950-1999 }\end{array}$ \\
\hline Progressive aspect & $\begin{array}{c}488 \\
(62 \%)\end{array}$ \\
\hline General imperfective aspect & 72 \\
& $(9 \%)$ \\
\hline Meanings derived from aspectual & 115 \\
& $(15 \%)$ \\
\hline Total aspectual & $\mathbf{6 7 5}$ \\
& $\mathbf{( 8 6 \% )}$ \\
\hline Subjective type 1 & 10 \\
(Subjective progressive with ALWAYS) & $(1 \%)$ \\
\hline Subjective type 2 \\
(Subjective progressive without ALWAYS)
\end{tabular}

Table 1: Functions of the progressive in British English (1950-1999)

The frequency differences make the analysis provided in the first part of this section plausible: the most common function of the progressive construction in PDE is to convey aspectual information. This means that the construction prototypically functions as a marker of progressive aspect: it is used to refer to dynamic situations viewed by the speaker without their boundaries. The aspectual uses where the aspectual meaning is extended to less typical contexts, whereby only certain facets of the typical progressive aspect meaning are applicable (i.e., the use with stative situations or "derived" uses), are less common, but together still constitute $24 \%$ of all uses. Altogether, aspectual meanings are clearly the more 
common ones, being present in $86 \%$ of all instances. Among the subjective uses, we see that the interpretative use is most frequent. This might have to do with the fact that interpretative uses are most clearly marked as a distinct type by occurring in contexts requiring an interpretation. However, the subjective use with ALWAYS is also quite clearly marked through the use of the adverbial, which is not common with the aspectual progressive (instances of the type shown in (5) are rare, since, as stated by Ljung, there are few situations in which dynamic events are endlessly in progress). It is thus surprising that the subjective progressive + ALWAYS is not more common, though this may have to do with the type of data (this type can be expected to occur more commonly in conversation than in written data). The scarcity of the subjective use without ALWAYS, on the other hand, is in accordance with the analysis offered above, as the niche left for this old vague meaning by the predominant aspectual uses and the other more clearly marked subjective uses can be expected to be quite small.

\section{The progressive in PDE as a case of functional layering}

We shall now turn to the diachronic background of the synchronic picture described above. Studying the historical development of the construction, one can see that the diversity of the functions of the PDE progressive represents a clear case of layering, in which older functions remain in place while newer functions develop.

$\mathrm{OE}$ and ME uses of the construction often seem to be stylistically motivated choices; their functions are not clear-cut. However, there do appear to be two main motivations for using the construction: on the one hand, it is chosen to highlight the durative or imperfective nature of a situation, as in (22) below, and on the other, it is used to highlight particularly remarkable situations, as in (23): ${ }^{13}$

13 In the present article, the view is taken that the present-day progressive represents the continuation of the $\mathrm{OE}$ construction beon/wesan + present participle rather than a continuation of the later and overall much less frequent form beon/wesan + preposition + gerund. Arguments against this approach based on the difference in meaning between the OE participial construction and the PDE progressive (e.g., Bybee et al. 1994: 132) cannot be considered valid, since the functional development can be shown to proceed with continuity from $O E$ to ME to ModE (cf. Kranich 2010b). Furthermore, a comparison of the OE use of the prepositional construction with the present-day use of the progressive also shows considerable functional differences (particularly if one follows De Groot 2007, who convincingly argues that the $\mathrm{OE}$ prepositional construction is an absentive). 
(22) Eala, eaw, hu hefig geoc he beslepte on eallæ $p a$ pæ on his tidu libbende wæron on eorðon

'Helas, oh, how heavy a yoke he laid on all who on his time were living on earth'

(Boethius, 39/31-33, example and translation from Nickel 1966: 254)

(23) Wæs he Mellitus mid lichoman untrymnesse mid fotadle swiðe gehefigad. . . he glaedlice all eorðlic ping wæs oferhleapende. . .

'Mellitus suffered severely from bodily infirmity..., but still, ..., he surmounted with alacrity all earthly obstacles...'

(Historia Ecclesiastica, 116, 28-30, example and translation from Hübler 1998: 69)

In instances of the type presented in (23), the progressive indicates that the speaker perceives the situation expressed in the predicate as somehow "remarkable" vis-à-vis the speaker's and/or the audience's "general background of expectations or norms [...] or to some particular background, e.g., a special wish or fear, a sympathy or antipathy, and the like" (Hübler 1998: 70). In (23), it is clearly a remarkable feat to surmount obstacles with alacrity, given the agent's infirmity.

These two main types of use have given rise to the diverse further developments leading to the present-day aspectual and subjective functions.

\subsection{The history of the aspectual functions}

The imperfective-durative use demonstrated in (22) seems to be the root of the progressive's current aspectual meaning, which has slowly crystallized in a process of secondary grammaticalization throughout the course of the modern period. ${ }^{14} \mathrm{In} \mathrm{OE}$ and $\mathrm{ME}$, this type of use is still found less frequently than the more

14 Secondary grammaticalization is understood as the process by which grammatical forms and constructions become more grammatical, e.g., by acquiring more clearly grammatical meanings. Primary grammaticalization, by contrast, is understood as the process by which lexical elements first become grammatical (cf. Traugott 2010: 38-41). With regard to the progressive, primary grammaticalization had already taken place by OE times, when the progressive must have emerged as a construction through reanalysis (cf. Traugott 1992: 188-189), while secondary grammaticalization can be said to have occurred mainly in the course of the ModE period, during which the function of the progressive construction became clearly aspectual. Further signs of increasing grammaticalization include paradigmaticization (the development of a formally marked passive) as well as increased bonding between the form of the auxiliary be and the present participle (cf. Kranich 2010b: 237-243). 
subjective uses (accounting for 43\% in OE and 28\% in the ME data from the Helsinki Corpus); in the Early Modern English period, however, it becomes responsible for a greater percentage of progressives (68\% of all uses) (percentages based on Killie 2008: 80, Table 2). In the 18th and 19th centuries, the aspectual use establishes itself as the dominant meaning of the construction. In the second half of the 17 th century, $80 \%$ of the progressives in ARCHER (80 out of 100 instances) are aspectual; in the second half of the 18th century, 94\% (168 out of 178) of progressives are aspectual. In this time, the progressive became a grammaticalized marker of aspect (cf. Kranich 2008, 2010b).

Regarding the general imperfective use, the present use with stative predicates could be seen as a continuation of older usages, as the construction was evidently not limited to dynamic events in OE (as Example 22 demonstrates). The present-day limitation to stative situations of limited duration is in fact a fairly recent development, becoming apparent in the 18th century (cf. Kranich 2010b: 189-191). One can presume that this restriction evolved hand in hand with the increasing establishment of the progressive function: since progressives typically refer to dynamic situations and dynamic situations can be expected to be most often temporary (cf. Ljung 1980: 28), the stative situations referred to with a progressive at least share the feature "temporary" with typical dynamic events. There seems to be a certain growth in its use with stative predicates in the 19th and 20th centuries (Smitterberg 2005: 174; Kranich 2010b: 148-154, 191-193), which could possibly be interpreted as an indication of the construction advancing down the grammaticalization cline from progressive to imperfective (a cline widely attested, cf. Bybee and Dahl 1989: 56-57; Heine 1994: 279-280). The apparently increasing acceptance of the progressive with stative verbs which had previously avoided it, e.g., understand, believe, love or hate (studied in Kranich 2010c) would seem to speak in favor of such an argument. However, one must note that when occurring with the progressive, these verbs are either used with dynamic properties (e.g., denoting a gradual increase of understanding) or else the progressive has subjective meaning, allowing it to occur with lexical input of any Aktionsart. The fact that these occurrences can be related to established principles of use discourages the notion of the progressive's further development into an imperfective (Kranich 2010c).

Of the derived aspectual functions, we can view the two future uses as related to the grammaticalization of the "progressive aspect" function. As we have said, both the "near future" use and the meaning of will/shall + progressive infinitive can be derived directly from the progressive aspect function. The data suggest that these derived functions became grammaticalized fairly recently: the near future use begins to reach a limited frequency in the late 19th century, while use of the will/shall + progressive only shows a certain increase in frequency in the late 
20th century (Nesselhauf 2007; cf. also Kranich 2010b: 179-186). Both types remain nonetheless rare. ${ }^{15}$

With regard to the combination perfect + progressive, on the other hand, it has already been noted in Section 3 that the meaning the progressive adds to the combination is vague and not clearly determined. In some instances, as in (18) above and (24) below, all the progressive appears to add is a certain focus on duration:

(24) She'd been following hounds all day, she said, by car; riders, horses, hounds, cars, all were plastered with mud.

(archerii\1950-99.bre\1975huxl.j9)

The situation is clearly not presented as open, since at the moment of speaking, the woman is not engaged in the activity. The effect of using a progressive (together with the adverbial all day) is merely to draw attention to the duration of the situation, which could be understood to be of remarkable length, considering the muddy weather. We might view this as rather similar to such earlier, vaguer uses of the construction as evidenced in (22): although the two situations have otherwise different properties, (in particular, (22) is stative, (24) dynamic), it can be noted that the effect of using a progressive rather than a simple form in the utterance only adds a focus on the duration of the event. Aristar and Dry (1982: 6-7) point out that the ModE progressive is used as a marker of progressive aspect, whereas in $\mathrm{OE}$, the construction marks the situation as having duration rather than as being in progress. But we may say that, in combinations with the perfect, the old meaning of the progressive lives on. The meaning of duration can be said to have found a "niche" in this particular combination, which is generally characterized by a semantic vagueness (König 1995, see Section 3).

\subsection{The history of the subjective functions}

Vezzosi (1996), Hübler (1998), Fitzmaurice (1998), and Killie (2008) have shown that the most common function of the progressive in $\mathrm{OE}$ is to foreground the situ-

15 Near future progressives represent 25 out of 496 progressives (5\%) in the time frame $1850-1899,42$ out of $667(6 \%)$ in 1900-1949, and 56 out of $783(7 \%)$ in 1950-1999, will/ shall + progressive use is even rarer, with less than 10 uses in all but the latest half-century found in ARCHER-2, where they make up 22 of 783 progressive uses (3\%). 
ation referred to. ${ }^{16}$ An example of this type of use was presented in (23), a further example can be found in what follows:

(25) Forðon nalæs æfter myclum fæce grimmre wræc pa pære fyrenfullan peode pæs grimman mannes wæs æfterfyligende.

'Therefore after no long time direr vengeance for their dire sin overtook this depraved people.'

(Historia Ecclesiastica, 50, 7-9, example and translation from Hübler 1998:

70)

The situation presented in the progressive, just as in (23), is clearly not imperfective. The situation in (23) is even punctual. The progressive construction is thus chosen, clearly not for its aspectual or duration-focusing value, but presumably because of its greater weight, which makes it a good candidate for the expression of emphasis. This use in fact seems to be the most frequent one in OE, as Killie's (2008) study shows. In her OE data (the OE section of the Helsinki Corpus), 21\% of the occurrences were classified as "narrative", i.e., used for emphasis in a narrative, while a further $22 \%$ were classified as "stative", meaning that the progressive was used with reference to a stative situation of unlimited duration and that the motivation for its use was also "most probably [that it] provides emphasis" (Killie 2008: 80). In the ME data in the Helsinki Corpus, a total of $72 \%$ of all instances fall into these two categories (i.e., they are either clearly or most probably emphatic), while this is true for $51 \%$ of the ME data found in Killie's own selection of texts (Killie 2008: 78, Table 1, 80, Table 2, 83, Table 3). Hence, one can conclude that $\mathrm{OE}$ and ME uses of the progressive are often motivated by the speaker's evaluation of the situation as somehow "remarkable", dramatic, or worthy of vivid description. In the EModE section of the Helsinki Corpus, by contrast, only $21 \%$ of all progressives are subjective (narrative or stative) (Killie 2008: 80, Table 2).

If one compares this $\mathrm{OE}$ use of the construction (to highlight the most remarkable events in a narrative) with the PDE subjective uses, one finds a difference resembling that observed in the case of the aspectual meanings: the function of the progressive in the OE uses is rather vague, while the PDE functions appear

16 Vezzosi (1996: 192-197) speaks of the foregrounding function of the construction. Hübler (1998), who presents a broad study of the use of grammatical devices as markers of speaker involvement using evidence from Bede's Ecclesiastical History, argues that the OE progressive mainly functioned as an "emotional index", marking the situation referred to by the predicate as somehow remarkable (cf. Hübler 1998: 70). Fitzmaurice (1998) studies the use of the progressive in the Anglo-Saxon chronicle and notes that the most dramatic events in the narrative are marked by this form. 
more clear-cut. With regard to the subjective uses, one sees a certain degree of specialization of progressive + ALWAYS as predominantly expressing negative speaker-attitude. The numbers in ARCHER-2 are too small to provide a fully satisfying quantitative picture (Kranich 2010b: 213-217), but an analysis of PDE data from the internet makes it seem likely that the combination, when used today, refers mostly to negatively-evaluated situations (Kranich 2007).

The interpretative use of the progressive also fulfills a rather specific function: it marks a proposition as reflecting the speaker's subjective interpretation of a circumstance which was either described more neutrally earlier or which is retrievable from the communicative context. This use also has emerged as a welldefined function only in recent times, the 19th century being the crucial period for its establishment (Kranich 2009, 2010b: 222-226). Its origins do not seem to lie in old subjective uses, but rather in the use of the progressive to mark referential identity between an unreal and a real situation (the former being compared to the latter), as seen in the following example:

(26) And behind him there was little Dutch, crawling with her belly down, and her eyes turned up at us, as if we were dragging her to be hanged.

(archerii $\backslash 1850-99 . b r e \backslash 1872$ blac.f6)

One may assume that this type of use represents an extension of the use of the aspectual progressive to express the simultaneity of two situations. There is a certain parallel between simultaneity, i.e., the expression of identical extension of two situations across time, and the referential identity of two expressions to the same situation. Both predications in (26) (crawl and be dragged to be hanged) refer to the same crawling event. The former expression describes the occurrence rather neutrally, while the second provides the speaker's more subjective interpretation of the event by means of a comparison. Especially in the earlier data, this structure (a comparative clause introduced by as if or as though) represents a common context for the interpretative progressive, which makes the assumption plausible that this may have been the critical context in which the interpretative function arose (cf. Kranich 2009, 2010b: 222-226 for a more detailed account).

The use of the subjective progressive without ALWAYS, on the other hand, is still rather similar to the OE use of the type evidenced in (23) and (25). It seems to linger throughout the history of the progressive without changing much apart from in its relative importance: Killie's (2008) study shows it to be the main motivation for using a progressive in OE. In the study of the complete ARCHER-2 data, its frequency of use hovers around the same rather low absolute frequencies throughout the 17th to 20th centuries, but since other uses, in particular the aspectual uses, have increased, its relative importance has decreased dramati- 
cally (Kranich 2008, 2010b: 217-222). We can thus say that the overall process of secondary grammaticalization is not accompanied by subjectification, as has been claimed repeatedly (see e.g., Wright 1994), but rather by objectification or de-subjectification, i.e., the loss of possible contexts for speaker-based meanings (cf. Kranich 2008, 2010a). Where there is no possible confusion with the more established grammaticalized function of the progressive, the form can however still be used occasionally to provide only a more emphatic description (as in Example 21), reflecting a much earlier stage of its functional development.

\section{The relation between aspectual and subjective meanings}

It is possible that the kind of development discussed here - that a periphrastic construction evolves from a construction used typically for foregrounding or emphasis to a marker of progressive aspect - is not unusual in the languages of the world. Güldemann (2003) shows that the development from focalizing construction to progressive has occurred in a remarkable number of Bantu languages, and also presents some evidence for similar developments in languages from other families. In Kranich (2010a), I discuss examples from Celtic and Romance languages of present-day progressive or imperfective markers which apparently used to have more subjective, emphatic functions in previous stages of development. There definitely seems to be a link here, but I believe that Güldemann (2003: 35) goes a little too far in speaking of an "amalgamation" of dynamic imperfectivity and focus of the utterance, which, according to him, is observable at least in the present tense sphere. After all, progressive markers can also be used to present backgrounded information, even in the present tense. Güldemann's proposal may fit the Bantu data very well, but regarding the English progressive, its early common use in subordinate clauses (more than half of the instances in the 17th century data from ARCHER-2, cf. Kranich 2010b: 129) and its common occurrence in contexts other than present tense (in all the fifty-year periods covered by ARCHER-2, more than half of all instances are NOT present tense, Kranich 2010b: 126) makes an explanation relying so heavily on pragmatic focus functions seem inappropriate.

An alternative suggestion would be that the English progressive, as well as the other Indo-European constructions addressed in Kranich (2010a), exhibit the development from more subjective to more aspectual for a different reason. Periphrases typically constitute the input of grammaticalizing progressives (cf. Bybee and Dahl 1989: 56). Before a periphrasis achieves the status of properly 
grammaticalized aspect marker, however, its additional weight as a construction longer than a mere verb makes it an attractive option for expressing something the speaker wishes to draw attention to (cf. also Ronan 2003: 142). This probably explains why the diachronic development of a construction with mostly vague foregrounding uses to a construction with more specialized and more grammatical functions is not uncommon, and why we often observe a synchronic state-ofaffairs in which a form fulfills both progressive aspectual functions as well as subjective functions.

\section{Conclusion and suggestions for the further applicability of the concept of functional layering}

Based on the results of a much more extensive study of the progressive in ModE (Kranich 2010b), the present article has attempted to show how the functions of the PDE progressive reflect in part older, less grammaticalized uses of the construction as well as partly representing the results of grammaticalization and (de-)subjectification processes.

The functional spectrum of the English progressive can thus be seen as the result of layering of less and more grammaticalized and less and more specialized subjective functions. In general, such a state of functional layering might be expected to be no rare phenomenon. Other examples include the use of the English perfect or the use of future will, where younger, more grammaticalized meanings may co-exist with meanings that were characteristic of earlier stages of grammaticalization. The perfect construction thus sometimes highlights current relevance, a less grammaticalized meaning, while at other times fulfilling the more grammaticalized function of marking anterior orientation (in Kortmann's (1991) terminology). The will + infinitive construction in English generally expresses neutral future reference. Yet in some contexts it has preserved its earlier meaning of volition (e.g., Will you marry me?) (cf. also Kranich 2010a). These few examples may suffce to demonstrate that the concept of functional layering can be applied to other constructions (particularly in the realm of TAM-markers) to account for their full synchronic meaning spectrum.

The present work has, on the one hand, highlighted the importance of a diachronic perspective for making sense of the semantic diversity of a construction in synchronicity. It has also stressed, however, that an adequate description of a construction needs to make sense of its variety of meanings in purely synchronic terms: it must explain how a hearer of the construction can arrive at an adequate 
interpretation. For this purpose, a model has been proposed that relies on contextual clues to make predictions as to which meaning will be assigned to a particular use of the progressive. Quantitative corpus results are very helpful in developing such a model, as the different frequencies of certain meanings help to distinguish prototypical, default meanings from niche meanings only assigned to a construction under more or less restricted conditions. Another clue as to the status of the different meanings may come once again from the diachronic development. After a grammaticalization process is completed, it is the meaning with the most fully grammaticalized status which gains the status of default meaning (cf. Dahl 2000), while older layers of meaning only survive in certain restricted contexts in a manner paralleling the niche survival attested for older layers of form shown by studies applying Hopper's original concept of layering (e.g., Hundt 2004: 112-113).

\section{References}

Aristar, Anthony \& Helen Dry. 1982. The origin of backgrounding tenses in English. In Kevin Tuite, Robin Schneider \& Robert Chametzky (eds.), Papers from the Eighteenth Regional Meeting of the Chicago Linguistic Society, April 15-16, 1982, 1-13. Chicago: Chicago Linguistic Society.

Bégin, Claude. 1996. Characterizing the type of outcome evoked by the perfect simple and the perfect progressive in English. Révue Québecoise de Linguistique 24. 39-52.

Bodelsen, C. A. 1974 [1936-1937]. The expanded tenses in Modern English. An attempt at an explanation. In Alfred Schopf (ed.), Der englische Aspekt, 144-162. Darmstadt: Wissenschaftliche Buchgesellschaft.

Bybee, Joan \& Östen Dahl. 1989. The creation of tense and aspect systems in the languages of the world. Studies in Language 13. 51-103.

Bybee, Joan, Revere Perkins \& William Pagliuca. 1994. The evolution of grammar. Tense, aspect and modality in the languages of the world. Chicago: The University of Chicago Press.

Chilton, Paul. 2007. Geometrical concepts at the interface of formal and cognitive models. Pragmatics \& Cognition 15. 91-114.

Comrie, Bernard. 1976. Aspect. An introduction to the study of verbal aspect and related problems. Cambridge: Cambridge University Press.

Comrie, Bernard. 1995. Tense and aspect. In Joachim Jacobs, Arnim von Stechow, Wolfgang Sternefeld \& Theo Vennemann (eds.), Handbücher zur Sprach- und Kommunikationswissenschaft. Vol. 9.2. Syntax. Ein internationales Handbuch zeitgenössischer Forschung. An international handbook of contemporary research, 1244-51. Berlin \& New York: De Gruyter.

Dahl, Östen. 1987 [1985]. Tense and aspect systems. Oxford: Blackwell.

Dahl, Östen. 2000. The tense-aspect systems of European languages in a typological perspective. In Östen Dahl (ed.), Tense and aspect in the languages of Europe, 3-25. Berlin \& New York: Mouton de Gruyter. 
Diewald, Gabriele. 2010. On some problem areas in grammaticalization studies. In Katerina Stathi, Elke Gehweiler \& Ekkehard König (eds.), Grammaticalization: Current views and issues, 17-50. Amsterdam \& Philadelphia: John Benjamins.

Dowty, David R. 1977. Toward a semantic analysis of verb aspect and the English "imperfective" progressive. Linguistics and Philosophy 1. 45-77.

Durst-Andersen, Per. 2000. The English progressive as picture description. Acta Linguistica Hafniensia 32. 45-103.

Fitzmaurice, Susan. 1998. Grammaticalisation, textuality and subjectivity: The progressive and the Anglo-Saxon Chronicle. In Dieter Stein \& Rosanna Sornicola (eds.), The virtues of language. History in language, linguistics and texts. Papers in memory of Thomas Frank, 21-49. Amsterdam \& Philadelphia: John Benjamins.

Goosens, Louis. 1994. The English progressive tenses and the layered representation of functional grammar. In Co Vet \& Carl Vetters (eds.), Tense and aspect in discourse, 161-177. Berlin \& New York: Mouton de Gruyter.

Granath, Solveig \& Michael Wherrity. 2008. 'Just what everybody is loving and wanting': A unified approach to so-called stative verbs in the progressive. Paper presented at the First Triennial Conference of the International Society for the Linguistics of English (ISLE 1), Freiburg, 8-11 October.

de Groot, Casper. 2007. The king is on huntunge: On the relation between progressive and absentive in Old and Early Modern English. In Mike Hannay \& Gerard J. Steen (eds.), Structural-functional studies in English grammar. In honour of Lachlan Mackenzie, 175-190. Amsterdam \& Philadelphia: John Benjamins.

Güldemann, Tom. 2003. Present progressive vis-à-vis predication focus in Bantu: A verbal category between semantics and pragmatics. Studies in Language 27(2). 323-360.

Hatcher, Anna Granville. 1974 [1951]. The use of the progressive form in English: A new approach. In Alfred Schopf (ed.), Der englische Aspekt, 177-216. Darmstadt: Wissenschaftliche Buchgesellschaft.

Heine, Bernd. 1994. Grammaticalization as an explanatory parameter. In William Pagliuca (ed.), Perspectives on grammaticalization, 255-287. Amsterdam \& Philadelphia: John Benjamins.

Hopper, Paul J. 1991. On some principles of grammaticization. In Elizabeth Closs Traugott \& Bernd Heine (eds.), Approaches to grammaticalization, vol. 1, 17-35. Amsterdam \& Philadelphia: John Benjamins.

Hübler, Axel. 1998. The expressivity of grammar. Grammatical devices expressing emotion across time. Berlin \& New York: Mouton de Gruyter.

Huddleston, Rodney D. \& Geoffrey K. Pullum. 2002. The Cambridge grammar of the English language. Cambridge: Cambridge University Press.

Hundt, Marianne. 2004. The passival and the progressive passive: A case study of layering in the English aspect and voice systems. In Hans Lindquist \& Christian Mair (eds.), Corpus approaches to grammaticalization in English, 79-120. Amsterdam \& Philadelphia: John Benjamins.

Joos, Martin. 1964. The English verb. Form and meaning. Madison: The University of Wisconsin Press.

Killie, Kristin. 2008. From locative to durative to focalized? The English progressive and 'PROG imperfective drift'. In Maurizio Gotti, Marina Dossena \& Richard Dury (eds.), English historical linguistics 2006, vol. I: Syntax and morphology, 69-88. Amsterdam \& Philadelphia: John Benjamins.

Klein, Wolfgang. 1994. Time in language. London: Routledge. 
König, Ekkehard. 1980. On the context-dependence of the progressive in English. In Christian Rohrer (ed.), Time, tense, and quantifiers: Proceedings of the Stuttgart Conference on the logic of tense and quantification, 269-291. Tübingen: Niemeyer.

König, Ekkehard. 1995. On analyzing the tense-aspect system of English: a state-of-the-art report. In Wolfgang Riehle \& Hugo Keiper (eds.), Anglistentag 1994 Graz: Proceedings, 153-169. Tübingen: Niemeyer.

Kortmann, Bernd. 1991. The triad 'tense - aspect - aktionsart': Problems and possible solutions. In Carl Vetters \& Willy Vandeweghe (eds.), Perspectives on aspect and aktionsart, 9-29. Brussels: Editions de l'Université de Bruxelles.

Kranich, Svenja. 2007. Subjectification and the English progressive. The history of ALWAYS + progressive constructions. York Papers in Linguistics (Series 2) 8. 120-137.

Kranich, Svenja. 2008. Subjective progressives in seventeenth and eighteenth century English. Secondary grammaticalization as a process of objectification. In Maurizio Gotti, Marina Dossena \& Richard Dury (eds.), English historical linguistics 2006, vol. I: Syntax and morphology, 241-256. Amsterdam \& Philadelphia: John Benjamins.

Kranich, Svenja. 2009. Interpretative progressives in Late Modern English. In Ingrid TiekenBoon van Ostade \& Wim van der Wurff (eds.), Current issues in Late Modern English, 331-357. Bern: Peter Lang.

Kranich, Svenja. 2010a. Grammaticalization, subjectification and objectification. In Katerina Stathi, Elke Gehweiler, \& Ekkehard König (eds.), Grammaticalization: Current views and issues, 101-121. Amsterdam \& Philadelphia: John Benjamins.

Kranich, Svenja. 2010b. The progressive in Modern English: A corpus-based study of grammaticalization and related changes. Amsterdam: Rodopi.

Kranich, Svenja. 2010c. I feel I am understanding it more now. A web-based study of stative verbs in the progressive in PDE. Paper presented at the 16th ICEHL (International Conference on English Historical Linguistics), Pécs, Hungary, 23-27 August.

Lass, Roger. 1997. Historical linguistics and language change. Cambridge: Cambridge University Press.

Leech, Geoffrey N. 1987. Meaning and the English verb, 2nd edn. London: Longman.

Leech, Geoffrey N., Marianne Hundt, Christian Mair \& Nicholas Smith. 2009. Change in contemporary English: A grammatical study. Cambridge: Cambridge University Press.

Lehmann, Christian. 2002 [1982]. Thoughts on grammaticalization, 2nd revised edn. Erfurt: Seminar für Sprachwissenschaft der Universität.

Leiss, Elisabeth. 2004. Submorphematische Motiviertheit als Grammatikalisierungsergebnis: Zur Grammatikalisierung von Reflexivpronomen. Zeitschrift für Germanistische Linguistik 32. 233-244.

Ljung, Magnus. 1980. Reflections on the English progressive. Gothenburg: Acta Universitatis Gothoburgensis.

Mair, Christian \& Marianne Hundt. 1995. Why is the progressive becoming more frequent in English? A corpus-based investigation of language change in progress. Zeitschrift für Anglistik und Amerikanistik 43. 111-122.

Michaelis, Laura. 2004. Type shifting in construction grammar: An integrated approach to aspectual coercion. Cognitive Linguistics 15. 1-67.

Mossé, Fernand. 1938. Histoire de la forme périphrastique être + participe présent en germanique, vol. Il. Paris: Klincksieck.

Mufwene, Salikoko. 1984. Stativity and the progressive. Bloomington, IN: Indiana University Linguistics Club. 
Nesselhauf, Nadja. 2007. The spread of the English progressive and its 'future' use. English Language and Linguistics 11. 191-207.

Nickel, Gerhard. 1966. Die Expanded Form im Altenglischen. Neumünster: Karl Wachholtz Verlag.

Palmer, Frank R. 1988. The English Verb, 2nd edn. London \& New York: Longman.

Quirk, Randolph, Sidney Greenbaum, Geoffrey Leech \& Jan Svartvik. 1985. A comprehensive grammar of the English language. London: Longman.

Ronan, Patricia. 2003. Periphrastic progressives in Old Irish. In Hildegard Tristram (ed.), The Celtic Englishes III, 129-149. Heidelberg: Winter.

Rydén, Mats. 1997. On the panchronic meaning of the English progressive. In Terttu Nevalainen \& Lena Kahlas-Tarkka (eds.), To explain the present: studies in the changing English language in honour of Matti Rissanen, 419-429. Helsinki: Société Néophilologique.

Smith, Carlota S. 1997. The parameter of aspect, 2nd edn. Dordrecht: Kluwer.

Smitterberg, Erik. 2005. The progressive in 19th-century English. A process of integration. Amsterdam: Rodopi.

Storms, G. 1964. The subjective and the objective form in Mdn English. English Studies: Supplement presented to $R$. W. Zandvoort on the occasion of his seventieth birthday. 57-63.

Traugott, Elizabeth Closs. 1972. A history of English syntax. New York: Holt, Rinehart \& Winston. Traugott, Elizabeth Closs. 1992. Syntax. In Richard Hogg (ed.), The Cambridge history of the English language, vol. I. The beginnings to 1066, 168-289. Cambridge: Cambridge University Press.

Traugott, Elizabeth Closs. 2010. (Inter)subjectivity and (inter)subjectification: A reassessment. In Hubert Cuyckens, Kristin Davidse \& Lieven Vandelanotte (eds.), Subjectification, intersubjectification and grammaticalization, 29-71. Berlin \& New York: De Gruyter Mouton.

Vezzosi, Letizia. 1996. La costruzione participio presente + verbo 'essere' in Anglosassone: Un antesignano della forma progressiva o qualcosa di diverso? Studi e Saggi Linguistici 36. 157-210.

Williams, Christopher. 2001. The progressive form and the non-progressive form in English: The theory of 'susceptibility to change'. CAUCE. Revista de Filologia y su Didactica 24. 87-117.

Williams, Christopher. 2002. Non-progressive and progressive aspect in English. Fasano di Puglia: Schena Editore.

Wright, Susan. 1994. The mystery of the modal progressive. In Dieter Kastovsky (ed.), Studies in Early Modern English, 59-77. Berlin \& New York: Mouton de Gruyter.

Žegarac, Vladimir. 1993. Some observations on the pragmatics of the progressive. Lingua 90. 201-220.

\section{Appendix: Data source}

ARCHER-2, A Representative Corpus of Historical English Registers 2. 19901993/2002. Compiled under the supervision of Douglas Biber and Edward Finegan at Northern Arizona University, University of Southern California, University of Freiburg, University of Helsinki, Uppsala University and University of Heidelberg. 